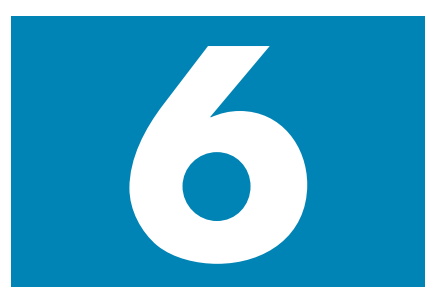

\title{
Analysing information
}

\author{
M. Grace
}

\section{The process of gathering information should remain completely separate from the process of analysing it, or else assumptions can be made that might lead the organisation into some hasty training without appreciating the full picture}

In this part, we will discuss:

\section{$\checkmark$ How many people are involved in order to achieve the business objectives? \\ $\checkmark$ Which people need to be fully trained? \\ $\checkmark$ What do people need to be competent at? \\ $\checkmark$ What do people need to know?}

$\mathrm{S}$ o far the emphasis throughout this series of articles has been on the collection of data only, and it is important to try not to draw any conclusions from any data you collect while collecting it. The process of gathering information should remain completely separate from the process of analysing it, or else assumptions can be made that might lead the organisation into some hasty training without appreciating the full picture.

Once the data has been collected then the training co-ordinator and whoever has responsibility for training (often the same person in a dental practice) need/s to start to analyse it.

\section{Where do we start}

For most people in business the obvious place to start an analysis is the information about what people need to do, in other words their job descriptions. In dental practice this is not always so obvious, partly because written job descriptions are still comparatively unusual, but also because it may appear inappropriate. After all, as most people know their job descriptions pretty well, there may be a justifiable feeling that it is unlikely to reveal any great surprises.

However, while the various jobs may contain some general common tasks in dentistry, each individual job can have substantial differences. No practice is alike, and no dental nurse's job is the same (as stated earlier ask any dental nurse who has worked for different practices). Besides, the main difficulty for a Training Needs Analysis (TNA) is the lack of a link between job descriptions and practice objectives. For example, in a busy dental prac- tice there is a natural tendency to focus on training needs related to clinical dentistry, especially by the dentists themselves. This often results in an emphasis on dental topics in all the training that is carried out, with little thought to other potential training needs. However, if one of the priority objectives of the practice is to raise the profile of the practice to a certain segment of the local community (such as local businesses or young families) then this should take preference over clinical topics in the analysis. Obviously clinical training is still important and certain clinical needs may overrule all others at times, but as far as the analysis goes the priority objectives must take preference.

So we start our analysis by setting priorities in the business objectives as to which are urgent and which are important. Figure 1 shows a short list of marketing objectives within the business objectives, with the need to increase the number of existing patients who become regular patients as a priority.

\section{Training objectives}

The next stage of the analysis is to consider the training objectives we set back in Part 3. How many people are involved in order to achieve the business objectives? Which people need to be fully trained? What do people need to be competent at? What do people need to know?

As explained earlier most of this information may be so obvious it seems unnecessary to write it down. However, writing it down helps us to distinguish between the more usual clinical objectives (often assumed and taken for granted) and the non-clinical objectives, so that we can get the full picture. Figure 2 is an example of a

\section{Fig. I Example marketing objectives for a dental practice}

\footnotetext{
${ }^{1}$ Editor, British Dental Journal, 64 Wimpole Street, London W1G 8YS ${ }^{*}$ Correspondence to: Mike Grace email:m.grace.bdj@bda-dentistry.org.uk REFEREED PAPER

(C) British Dental Journal

2001; 191: 67-70
}

Marketing

- To increase the number of regular patients who return to the practice for regular (6-18 monthly) dental visits to $80 \%$ of the total patient base by 31 December 2002

- To develop a full-time hygienist service by I September 2002

- To raise the profile of the practice in the local business community to a $75 \%$ awareness level by 3 I December 2002

- To achieve $95 \%$ customer satisfaction in non-clinical care by | September 200 | 


\section{Fig. 2 A training objective for dental practice on customer care}

To ensure that all members of the practice involved in patient contact are fully aware of the practice customer care policy and are capable of delivering appropriate levels of customer care to all patients they come into contact with. On-going.

(c) UMD Professional Ltd

\section{Fig. 3 SEQs}

\section{TED}

\begin{tabular}{|l|c|c|}
\hline TASKS/SKILLS/PROCESSES & Ability & Knowledge \\
\hline & & \\
\hline Keeping patients informed at all times & $\bullet$ & $\bullet$ \\
\hline Communicating treatment options effectively & $\bullet \bullet$ & $\bullet \bullet$ \\
\hline Achieving patient acceptance on treatment plans & $\bullet \bullet$ & $\bullet$ \\
\hline Achieving win/win results when people complain & $\bullet$ & $\bullet$ \\
\hline A good understanding of the complaints procedure & $\bullet$ & $\bullet$ \\
\hline Checking patients feel good about their exit procedure & $\bullet$ & $\bullet$ \\
\hline & & \\
\hline
\end{tabular}

\section{CHRISTINE}

\begin{tabular}{|l|c|c|}
\hline TASKS/SKILLS/PROCESSES & Ability & Knowledge \\
\hline & & \\
\hline Keeping patients informed at all times & $\bullet$ & $\bullet$ \\
\hline Communicating treatment options effectively & $\bullet$ & $\bullet$ \\
\hline Achieving patient acceptance on treatment plans & N/A & N/A \\
\hline Achieving win/win results when people complain & $\bullet$ & $\bullet$ \\
\hline A good understanding of the complaints procedure & $\bullet$ & $\bullet$ \\
\hline Checking patients feel good about their exit procedure & $\bullet$ & $\bullet$ \\
\hline & & \\
\hline
\end{tabular}

SHULA

\begin{tabular}{|l|c|c|}
\hline TASKS/SKILLS/PROCESSES & Ability & Knowledge \\
\hline & & \\
\hline Keeping patients informed at all times & $\bullet$ & $\bullet$ \\
\hline Communicating treatment options effectively & $\bullet$ & $\bullet$ \\
\hline Achieving patient acceptance on treatment plans & N/A & N/A \\
\hline Achieving win/win results when people complain & $\bullet$ & $\bullet$ \\
\hline A good understanding of the complaints procedure & $\bullet \bullet \bullet$ & $\bullet \bullet \bullet$ \\
\hline Checking patients feel good about their exit procedure & $\bullet \bullet$ & $\bullet$ \\
\hline & & \\
\hline
\end{tabular}

(c) UMD Professional Ltd possible training objective we might have set related to the business objective of retaining 20 patients a month as regular patients (measured by the fact they book into the practice recall programme). Note that this training objective does involve everyone in the practice.

With our priority business objective clear and the resultant training objective defined we can now start to analyse the information with much greater focus. Had we not carried out these two steps first we might have been distracted by some obvious areas of training need that were identified in interviews, at an appraisal meeting or by using the Self Evaluation Questionnaires (SEQs). This could have distracted us from the real need. The importance of objectives cannot be overstressed, as the objectives drive all the other activities of the practice.

\section{The 'blobby' charts}

Many people find the SEQs (or blobby charts as they are often called) a good place to start analyzing the data we have collected. One reason is the fact they are clear, quantitative and should make it easier to identify areas where people perceive a lack of knowledge or skill.

Figure 3 shows the three separate SEQs for three individuals in a practice with an objective of retaining existing patients. The people in this example form part of a team for the practice made up of an associate dentist (Ted), a dental nurse (Christine) and one of the reception team (Shula). In a small practice they might form the entire practice, in a larger one they form a subteam. Note that one section of the SEQ has been marked as 'not applicable' (N/A) by Christine and Shula who would obviously not be involved in direct patient acceptance of treatment plans.

Before we analyse the SEQs we need to estimate what we expect their ideal levels of knowledge and ability to be. In the areas selected for this example the ideal levels are shown in Figure 4a under the column marked 'IDEAL' on the left. The number of 'blobs' in the ideal column is not intended to suggest this is appropriate for every practice, but is simply the choices of the owner of the practice. Each dentist would almost certainly have different ideas, and there is obviously no 'right' ideal. Also, in this case, the section that is applicable only to the dentist is marked as a reminder.

Having identified the ideal number of 'blobs' we can quickly see where the gaps lie. Figure $4 a$ illustrates the situation very clearly, and a quick glance tells us that there are a number of areas where a single blob shows a perceived area of need for each person in the team. However, Figure $4 \mathrm{~b}$ is a better way of analyzing exactly where the priorities are. On the right of the form is the total number of blobs required if we are to achieve the ideal for all three people (Ideal x3). Next to this is the actual number and the final column shows the difference. 


\section{Fig. 4 Analysis of SEQs in Figure 3}

(a)

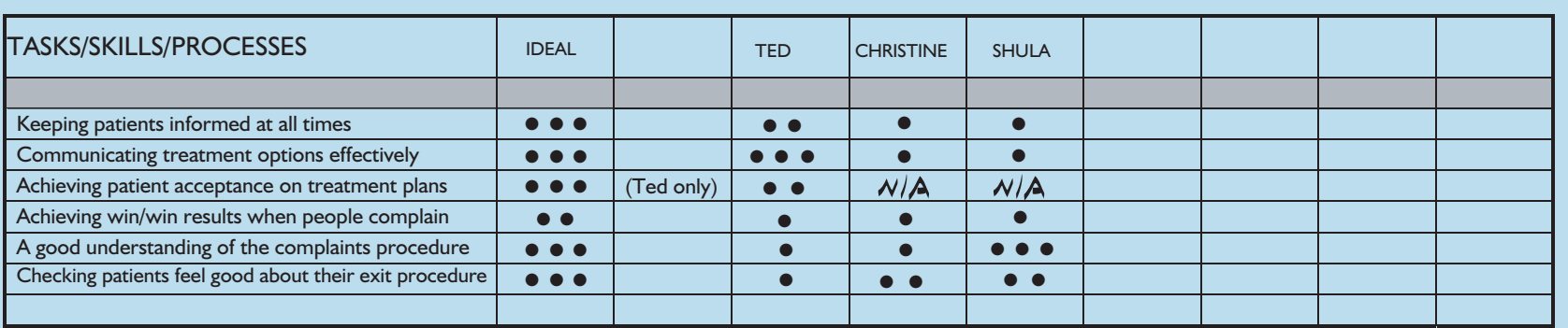

(b)

\begin{tabular}{|l|c|c|c|c|c|c|c|c|c|}
\hline TASKS/SKILLS/PROCESSES & IDEAL & & TED & CHRISTINE & SHULA & & $\begin{array}{c}\text { TOTAL } \\
\text { NEEDED }\end{array}$ & ACTUAL & DIFFERENCE \\
\hline & & & & & & & & & \\
\hline Keeping patients informed at all times & $\bullet \bullet$ & & $\bullet \bullet$ & $\bullet$ & $\bullet$ & & 9 & 4 & -5 \\
\hline Communicating treatment options effectively & $\bullet \bullet \bullet$ & & $\bullet \bullet$ & $\bullet$ & $\bullet$ & & 9 & 5 & -4 \\
\hline Achieving patient acceptance on treatment plans & $\bullet \bullet \bullet$ & $($ Ted only) & $\bullet \bullet$ & N/A & N/A & & 3 & 2 & -1 \\
\hline Achieving win/win results when people complain & $\bullet \bullet$ & & $\bullet$ & $\bullet$ & $\bullet$ & & 6 & 3 & -3 \\
\hline A good understanding of the complaints procedure & $\bullet \bullet \bullet$ & & $\bullet$ & $\bullet$ & $\bullet \bullet \bullet$ & & 9 & 5 & -4 \\
\hline Checking patients feel good about their exit procedure & $\bullet \bullet \bullet$ & & $\bullet$ & $\bullet \bullet$ & $\bullet \bullet$ & & 9 & 5 & -4 \\
\hline
\end{tabular}

Based on this the first area ('Keeping patients informed at all times') on this part of the SEQ is the first priority.

In this example the actual number of blobs has been marked just for ability. A separate chart can be used for knowledge if required. It is immediately easy to see the overall areas of need and the individual areas for each person. Remember these SEQs only act as guides, and are helpful in analyzing the overall situation, bearing in mind that other factors have to be taken into account.

You can choose how you analyse individuals within this kind of structure, as Figure 4 is only one example. You may choose to transfer the blobs onto an overall chart for knowledge and ability at the same time, or simply highlight areas with a single blob to get an overall feel for training needs. The method of analysis is obviously up to you.

\section{Interviews}

The other method you may find useful is the interview, whether as part of an appraisal or separately. The usual rules for interviewing people apply, such as asking open questions, probing into certain areas where applicable, listening to the answers and making notes. In the case of this type of interview though the process is aimed at the two people working together to identify which areas of training need are the most appropriate for training, and the interviewee may have a clearer idea of her or his competencies and confidence than the interviewer.
Analysing interviews means simply looking at what was said as objectively as possible and including the information in the overall analysis. It is hardly ground-breaking material.

\section{Identifying the gaps}

The purpose of the analysis is to identify where gaps exist between what the individual should be good at doing and what he or she should know - and what the real situation is.

Thus the analysis will often end up with a list of areas where gaps exist. The priority of which gaps exist and which to attend to first depends on the priority of the objectives. Thus, if someone has some gaps in knowledge and ability in both customer care and team-working, it might be sensible to focus on the customer care gaps if the primary objective at the moment is to retain patients by increasing customer care. If a motivated and effective team was the higher priority then perhaps the gap in team-working is more important. The choice would be down to the dentist. An example of such a list is provided in Figure 5.

It is important to identify both current and future gaps as well. Thus, a practice moving toward a more preventive philosophy over the next 2 years might consider periodontal knowledge as a future area to be included, and any gaps identified accordingly.

\section{Rationalisation}

One of the difficulties of ensuring a TNA is genuine and cost-effective is to recognise the natural tendency to rationalise. In other words, we
Identifying the gaps: The purpose of the analysis is to identify where gaps exist between what the individual should be good at doing and what he or she should know - and what the real situation is. 


\section{Fig. 5 Some current gaps in knowledge and skills identified in the TNA}

\section{Current Training Needs Analysis}

\section{Caroline Draymore (associate dentist)}

\section{Clinical}

Periodontal monitoring

Root planing

\section{Management}

Strategic forecasting

Decision-making

Time management

Marketing

Customer care

Selling ethically

\section{Claire Holbrook (practice manager)}

\section{Management}

Recruitment and selection

Interviewing

Running effective meetings

\section{Marketing \\ Selling ethically \\ Practice promotion}

\section{Administration}

Office management systems

Basic financial management

IT

Basic spreadsheet knowledge (c) UMD Professional Ltd

(C) 1999 The design of the SEQs in this article are copyright of UMD Professional Limited can fool ourselves that an area of training is really important and relevant because it is an area that interests us.

For example, a dentist could have an objective of attracting new patients to the practice. He wants to go on a course about implants, even though he has little intention of fitting implants himself, but simply because he wants to go. He rationalises that this is a sensible choice for training because (he tells himself) being able to identify patients for implants and refer them will attract more patients.

While this may be true, it is not as likely as other methods of marketing that he has not considered. The question he needs to ask himself is 'Is there a better, easier or cheaper way of meeting the objective of attracting new patients?' The answer is definitely a 'probably' and before he books himself onto the implant course he must be sure that the money would not be better spent elsewhere.

This is a hard and difficult lesson for people to learn when they actually want to attend certain courses for their own enjoyment rather than as a business investment for the benefit of the practice as a whole.

\section{Inappropriate data}

One of the difficulties of analyzing information collected in a very non-scientific way is having confidence in the data itself. The SEQs are obviously open to misinterpretation, as some people will mark themselves too high or too low. Questionnaires can simply report what people want to tell you, and CVs have been known to paint more optimistic experiences in the past than the actuality.

Despite these disadvantages, a TNA will often provide surprisingly good data, and will often prove that self-perception can be very accurate. Even if people do misjudge or even deceive, the data itself will form the basis for discussion at the appraisal. You can ask people why they think they are good/bad at something if your own observation differs from their perception. Sometimes they will be right and your observation will be wrong.

\section{Conclusion}

This chapter has looked at specific methods of analyzing information collected via a training needs analysis. The focus has been on SEQs, mainly because they are so easy to use. Despite the possible faults of SEQs they act as an indicator, and if nothing else will stimulate discussion.

Analysing all the data collected via a TNA will open up possible areas where gaps exist between the ideal competence and confidence of people (as assessed by the manager) and their own perceptions of their knowledge and ability. The key to effective training though is the need for all training to focus on people's needs related to the business and training objectives of the organization. Not doing so is a recipe for wasted money, time and effort. 